\title{
Erratum to: The Effect of Behavioral Family Intervention on Knowledge of Effective Parenting Strategies
}

\author{
Leanne Winter $^{1} \cdot$ Alina Morawska ${ }^{1} \cdot$ Matthew R. Sanders $^{1}$
}

Published online: 20 March 2015

(C) Springer Science+Business Media New York 2015

\section{Erratum to: J Child Fam Stud (2012) 21:881-890 DOI 10.1007/s10826-011-9548-y}

\section{Authors' Statement of Conflict of Interest}

The Triple $\mathrm{P}$-Positive Parenting Program is owned by the University of Queensland. The University through its main technology transfer company, UniQuest Pty Ltd, has licensed Triple P International Pty Ltd to publish and disseminate the program worldwide. Royalties stemming from published Triple $\mathrm{P}$ resources are distributed to the Parenting and Family Support Centre; School of Psychology; Faculty of Health and Behavioural Sciences; and contributory authors. No author has any share or ownership in Triple P International Pty Ltd. Alina Morawska is an author of various Triple P programs. Matthew R. Sanders is the founder and an author on various Triple $\mathrm{P}$ programs and a consultant to Triple P International.

The online version of the original article can be found under doi:10. 1007/s 10826-011-9548-y.

Leanne Winter

l.winter@uq.edu.au

1 School of Psychology, Parenting and Family Support Centre,

The University of Queensland, Brisbane, QLD 4072,

Australia 